\title{
O DEVER FUNDAMENTAL DE PROTEÇÃO À CRIANÇA E AO IDOSO COMO FUNDAMENTO DO BENEFÍCIO DE AUXÍLIO DOENÇA PARENTAL
}

\author{
THE BASIC DUTY OF CHILD AND ELDERLY PROTECTION AS A \\ FOUNDATION OF PARENTAL DISEASE AID BENEFIT
}

\author{
Priscilla Severo ${ }^{\mathrm{I}}$ \\ Clovis Gorczevski ${ }^{I I}$
}

\footnotetext{
${ }^{\mathrm{I}}$ Universidade de Santa Cruz do Sul, Santa Cruz do Sul, RS, Brasil. Mestranda em Direito. E-mail: priscillasevero@ hotmail.com

II Universidade de Santa Cruz do Sul, Santa Cruz do Sul, RS, Brasil. Doutor em Direito. E-mail: clovisg@unisc.br
}

\begin{abstract}
Resumo: A presente pesquisa tem como objetivo ressaltar a importância da criação do Auxílio-Doença Parental, face a inexistência de proteção a este risco social que afeta a dignidade da pessoa humana, além de atingir a proteção integral à criança e o amparo aos idosos, ambos assegurados constitucionalmente. A problemática do trabalho consiste em demonstrar de que forma a legislação de proteçáo às crianças e idosos contribui na fundamentação da criação do Auxílio-Doença Parental. Inicialmente, foi abordado o dever ético de cuidado presente nas relaçóes familiares geração após geração. Após, abordou-se a teoria da proteção integral à criança e a importância da tutela especial em consideraçáo a sua condição de desenvolvimento. Seguidamente, demonstrou-se a proteção especial aos idosos e a necessidade de garantia de uma velhice digna. Por fim, demonstrouse o conceito do Auxílio-Doença Parental e os benefícios da sua criação às famílias, em especial às crianças e idosos. Utiliza-se a metodologia dedutiva e como técnica de pesquisa a bibliográfica que consiste, basicamente, na pesquisa e interpretação doutrinária.
\end{abstract}

Palavras-chave: Previdência Social. Políticas Públicas. Criança. Idoso. Auxílio-doença Parental.

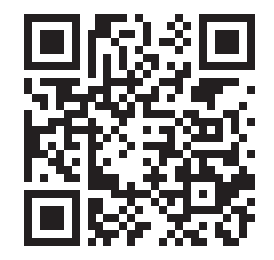

DOI: http://dx.doi.org/10.31512/rdj.v21i39.308

Recebido em: 07.09.2019

Aceito em: 21.07.2020
Abstract: The goal of this research is to emphasize the importance of the creation of Parental Aid-Disease, given the lack of protection of this social risk that affects the dignity of the human person, in addition to achieving full protection for the child and protection for the elderly, both assured constitutionally. The problem of the work is to demonstrate how the legislation to protect children and the elderly contributes to the creation of the Parental HelpDisease. First, it was approached the ethical duty of care present in family relations in all generation. Afterwards, the theory of integral protection to the child and the 
importance of the special guardianship in considering their condition of development were approached. Next, special protection for elderly people and the need to guarantee a dignified old age were demonstrated. Finally, the concept of Parental Help was demonstrated and the benefits of its creation to families, especially children and the elderly. The deductive methodology is used as a bibliographical research technique that basically consists of re-search and doctrinal interpretation.

Keywords: Social Security; Public policy; Child; Elderly; Parental Aid-Disease.

\section{Consideraçóes iniciais}

As relaçóes familiares representam a estrutura basilar dos indivíduos enquanto seres humanos em constante desenvolvimento. Nessa perspectiva, quando há o nascimento de uma criança na família, nasce um vínculo poderoso de afeto e corresponsabilidade, inclusive material.

A primeira responsabilidade é com as crianças na formação e desenvolvimento destas, enquanto na vida adulta forma-se o sentimento mútuo de cuidado entre os membros da família, até o momento que as crianças que um dia foram cuidadas pelos seus pais tornam-se os responsáveis legais e afetivos por eles que se encontram em situação de vulnerabilidade em razão do envelhecimento.

Partindo desse pressuposto, as relaçóes familiares são de suma importância na formaçáo dos indivíduos, enquanto seres humanos, e na evoluçáo da sociedade, enquanto seres que convivem em coletividade. Nessa conjuntura, a proteção às famílias pela legislação constitucional e infraconstitucional são imprescindíveis.

Nota-se que as condições de vulnerabilidade das crianças e dos idosos são reconhecidas pela Constituição Federal que expressamente determina a tutela especial a estes, além de estabelecer a tripla responsabilidade compartilhada entre família, Estado e sociedade.

\section{Dever ético do cuidado}

Os seres humanos são seres que convivem em coletividade necessitando desta convivência para se desenvolver, produzir e evoluir, promovendo e fomentando a solidariedade. Em tempos de neoliberalismo, tem-se visto o perdimento do espírito solidário entre os indivíduos, fruto da constante competitividade e concorrência uns com os outros, na busca desenfreada por vantagens individuais.

Nesse compasso, considerando que os indivíduos são dotados de oportunidades e limitaçôes diversas entre si, revela-se necessário o tratamento diferenciado e o amparo aos mais 
vulneráveis, na medida de suas desigualdades. É por esta razão que os indivíduos devem assumir o seu papel como membro de um coletivo, utilizando como princípio basilar a solidariedade.

Em se tratando de seres coletivos o cuidado revela-se inerente enquanto indivíduo e para com os seus pares, já que a todo o momento os seres humanos encontram-se cuidando uns aos outros, pela simples razão de fazer parte da concepção humana. Em outras palavras, para que seja possível o desenvolvimento do indivíduo, o cuidado é inerente a sua própria pessoa e aos outros em razão da condição de ser-humano. Nota-se que ao nascer, de regra, o indivíduo será amparado pela sua família até que ele adquira consciência dos seus atos e condiçóes suficientes para que possa se auto administrar. Isso não significa afirmar que a partir dessa consciência o cuidado termina: este apenas vai se moldando de acordo com as necessidades de cada indivíduo.

Embora esta situação seja inerente à pessoa humana, é possível observar certa negligência com o cuidado em todos os setores, fruto da sociedade neoliberalista que assola a população mundial e o desenvolvimento do individualismo. Neste contexto, destaca-se governos preocupados apenas com a situação fiscal e econômica do país, negligenciando o cuidado com a população; indivíduos negligenciando os cuidados com a natureza em detrimento de lucros, vantagens ou comodismo pessoal. É possível visualizar a sociedade muito mais preocupada com o "ter" do que com o "ser", afastando-se da responsabilidade do cuidado e do bem-estar da coletividade.

Em contrapartida, constantemente é possível presenciar situaçôes de cuidado: os pais, os enfermeiros do hospital, os professores da escola, os médicos, os advogados, os cuidadores de crianças e idosos. Seja por obrigação, salário, voluntariado, familiar ou não; o cuidado deve ter a ética como valor basilar.

Em termos gerais, a origem da palavra ética origina-se de éthos, termo de origem grega que traduz o conjunto de costumes ou propriedade do caráter. Para os gregos, esse vocábulo significava costume social, hábitos e o modo de comportamento próprio de determinada sociedade (MARCONDES, 2009).

Em se tratando de discussão acerca do cuidado com o ser humano, destaca-se a ética do cuidado direcionada instantaneamente à relação de gênero, considerando a atribuiçáo de cuidado (quase que) automática às mulheres determinada pela sociedade. Embora os movimentos feministas históricos refletem conquistas de visibilidade à questão de gênero e busca pela igualdade política à população feminina ${ }^{1}$, é visível a responsabilização natural e inerente às mulheres sobre o tema.

Sob a perspectiva histórica, o cuidado maternal e feminino que antes era atribuição principal designada às mulheres molda-se de acordo com a evoluçáo da sociedade. Nesse ritmo, a ampliação do mercado de trabalho ao gênero feminino, atribui a este a responsabilidade tanto

1 Nesse sentido destaca-se a importância das revoluçóes Americana e Francesa como inspiraçóes para a luta das mulheres para ter reconhecido a sua condição de sujeito de direito, dando início ao movimento sufragista no período de 1850 - 1930. Ainda, a revolução Francesa ganha destaque no sentido de expor que a opressão das mulheres existia em todas as classes sociais (GORCZEVSKI; MARTIN, 2011). 
o trabalho externo quanto aos cuidados familiares e domésticos, sob análise cumulativa ${ }^{2}$, sendo esta uma das justificativas para que haja a constante busca pela igualdade material entre homens e mulheres.

A verdade é que o cuidado paira nas relaçóes cotidianas todos os dias e em qualquer momento. Tanto é assim que, analisando a questão do desenvolvimento das políticas públicas de proteçáo social, é possível observar que, a referência de proteção social começou muito mais cedo que a intervenção do Estado nas políticas de concessão social junto às famílias, na medida em que os mais jovens e os aptos para o trabalho cuidavam e promoviam o sustento dos idosos e dos incapazes, o que se assemelha à sistemática do modelo de Seguridade Social atualmente constituído pela Constituição Federal de 1988 (IBRAHIM, 2012).

Nesse sentido, embora o cuidado esteja em todas as relaçôes cotidianas, este é visível de forma mais atuante para com as crianças considerando a sua condição de vulnerabilidade em comparação aos adultos e o seu grau de desenvolvimento como indivíduo. Por esta razão, analisese a seguir a criança como sujeito de direito de proteção prioritária e integral aos cuidados dos pais, do Estado e da sociedade, conforme dispóe a determinaçáo inserida no texto constitucional e nas leis esparsas de proteção a estes sujeitos em desenvolvimento.

\section{Proteção integral às crianças}

A construção da tutela integral às crianças é resultado de um longo processo de reconhecimento da importância do seu desenvolvimento com qualidade e dignidade, além do reconhecimento da sua condição de vulnerabilidade perante a sociedade, por se tratarem de seres em desenvolvimento. Analisando o processo histórico de forma geral, as crianças antes detentoras de status de seres inferiores são reconhecidas como sujeito de direitos, além de receber proteção integral e prioritária ${ }^{3}$.

Para que seja possível analisar a tutela conquistada às crianças de forma mais completa, importante mencionar o caminho percorrido para tanto. Em se tratando de crianças, cumpre destacar que "a raiz etimológica da expressão criança denota criação, fazer crescer" (CUSTÓDIO, 2006, p. 18). Nota-se que se trata de ser em condição de vulnerabilidade, razão pela qual merece análise cuidadosa e especial.

2 Fala-se em jornada dupla ou tripla de trabalho em razão da sua inserção no mercado de trabalho e permanência da responsabilidade com os afazeres da casa e nos cuidados com os filhos.

3 A história da infância no Brasil foi marcada por três grandes períodos. "O período pré-republicano, compreendido entre 1500 e 1889, tem em comum uma visão tênue da infância na medida em que são incipientes as práticas de intervenção no universo infantil representadas principalmente pelas primeiras iniciativas no campo da educação, da assistência e saúde. O período da primeira república apresenta significativas transformaçōes no modo de percepção e intervenção no universo infantil. É um período de grandes transformações envolvendo os anos compreendidos entre 1889 até 1927, quando foi editado primeiro Código de Menores. Já o período do Direito do Menor envolve três momentos significativos, desde a aprovação do primeiro Código em 1927, a adoção da Política Nacional do Bem-Estar do Menor, em 1964 e a doutrina da situação irregular de 1979, que vigoraria até a promulgação da Constituição da República Federativa do Brasil, em 05 de outubro de 1988" (CUSTÓDIO, 2006, p. 18). 
Esse cuidado nem sempre foi uma realidade na proteção as crianças que, por longo período foram indivíduos sem qualquer possibilidade de demonstrar seus desejos e anseios. Tanto é assim que a construção social da infância foi realizada sob olhar dos adultos que as tratavam sob condição de inferioridade, fruto de uma sociedade patriarcal e desigual. Ao mesmo tempo que "a criança brasileira foi órfă, abandonada, delinquente, escrava, menor, trabalhadora; [...] também pura, ingênua, bela e até promessa de futuro” (CUSTÓDIO, 2006, p. 19).

A cultura em diminuir as crianças, chamando-a de "menor", "pequena”, "miúda", refletiu diretamente no sistema jurídico brasileiro que, por longo período, também a tratou desta forma. Tanto é verdade que houve a transição da Doutrina da Situação Irregular, disposta no Direito do Menor para a Doutrina da Proteção Integral, disposta no Direito da Criança e do Adolescente (CUSTÓDIO, 2008).

Nesse sentido, o desenvolvimento da sociedade e dos direitos humanos, possibilitou que a criança que antes não era considerada detentora de direito, passasse à condição de "sujeitocidadão" (VERONESE, 2013, p. 50) e a ser vista com outro olhar capaz de torná-la titular de direitos que antes alcançava apenas os adultos. Não apenas tornaram-se protegidas por direitos já instituídos, mas também alcançaram uma esfera de tutela integral aos direitos. Nesse sentido, cabe destacar que

o reconhecimento da criança como sujeito de direitos é uma conquista muito recente no direito brasileiro, pois durante o maior período da história brasileira, encerrava-se apenas como uma promessa de futuro. A adoçấo da doutrina da proteção integral na Constituição da República Federativa do Brasil em 1988 foi o marco fundamental de todo esse processo de transformação jurídica (CUSTÓDIO, 2006, p. 20).

O texto constitucional de 1988 representa a base fundamental na tutela da Criança e do Adolescente na formação de programas e diretrizes, pois além de consolidar um novo ramo jurídico através do Direito da Criança e do Adolescente, revogou a Doutrina do Direito Menor e a Doutrina da Situação Irregular (CUSTÓDIO, 2006). A partir do art. 227 da Constituição Federal de 1988 encontra-se a determinação da tríplice responsabilidade compartilhada como forma de assegurar e efetivas a proteção integral às crianças e adolescentes ${ }^{4}$.

No campo histórico, o primeiro documento a destacar direitos à criança foi a Declaração de Genebra, de 26 de setembro de 1924, representando importante marco inicial da teoria da proteção integral, destacando direitos como o desenvolvimento normal e acesso as condiçóes materiais, morais e espirituais, independente de crença, raça ou nacionalidade (CUSTÓDIO, 2006).

Na sequência, a Declaração Universal dos Direitos Humanos de 1948, considerada como marco na condução do direito social a nível mundial, representa um documento internacional

4 É dever da família, da sociedade e do Estado assegurar à criança, ao adolescente e ao jovem, com absoluta prioridade, o direito à vida, à saúde, à alimentação, à educação, ao lazer, à profissionalização, à cultura, à dignidade, ao respeito, à liberdade e à convivência familiar e comunitária, além de colocá-los a salvo de toda forma de negligência, discriminação, exploração, violência, crueldade e opressão (BRASIL, 1988, www.planalto. gov.br). 
que declarou forte proteção dos direitos humanos como conteúdo basilar, além de evidenciar a importância da participação dos cidadãos na busca pela igualdade e solidariedade na sociedade. O seu texto traz fundamentos à formação da teoria da proteção integral quando, inclui em seu art. 25 a proteção social necessária às crianças, além de destacar a proteção à família (REIS, 2015).

A proteção às crianças disposta nestes textos internacionais é fundamental para embasar a formação da Declaração Universal dos Direitos da Criança, aprovada pela Assembleia Geral das Naçóes, no ano de 1959. A partir da leitura do seu texto, é possível destacar que esta representa "[...] o primeiro conjunto de valores da Doutrina da Proteção Integral” (CUSTÓDIO, 2006, p. 126).

Denota-se que a formação da teoria da proteção integral às crianças, como as demais teorias, é resultado de longo e gradativo processo de reconhecimento destas como sujeitos de direito, ao passo que somente foi possível "a partir da compreensão da infância enquanto construção social” (REIS, 2015, p. 23).

Nesse processo de ampliação da proteção às crianças, a Convenção Internacional dos Direitos da Criança aprovada com unanimidade pela Assembleia das Naçóes Unidas, em sua sessão de 20 de novembro de 1989 e ratificada pelo Brasil em 24 de setembro de 1990, por meio do Decreto no 99.710/1990 representa um marco importante na garantia da tutela especial às crianças, indo de encontro também ao conteúdo material dos direitos humanos, uma vez que a condição de pessoa é o requisito único para a titularidade de direitos, abrangendo, por óbvio, as crianças (BRASIL, 1990, www.planalto.gov.br).

A Convenção sobre os Direitos da Criança, traz em seu preâmbulo, diretrizes bases na proteção das crianças ao reconhecer que todo indivíduo é detentor de dignidade e de direitos humanos iguais e inalienáveis. Referido documento faz ressalva ainda, a condição de vulnerabilidade que atingem a criança, motivo pelo qual reconhece a importância que a criança, para o pleno e harmonioso desenvolvimento de sua personalidade, deve crescer no seio da família, em um ambiente de felicidade, amor e compreensão (BRASIL, 1990, www.planalto.gov.br).

Diversamente da Declaração Universal dos Direitos da Criança, que traz sugestóes ao Estado na proteçáo aos direitos da criança, a Convençáo sobre os Direitos da Criança traz, além de destacar princípios e direitos necessários na proteção do desenvolvimento da criança, traz em seu texto deveres ao Estado, de cunho coercitivo. Referido documento tem força de lei internacional, além de trazer mecanismos de controle das obrigaçóes em face dos Estados que o ratificam (VERONESE, 2013).

Da mesma forma, a teoria da proteção integral é fundamento base para a criação do Estatuto da Criança e do Adolescente, que complementa a proteção constitucional absoluta às crianças, positivando o conceito de proteção integral, além de disciplinar formas de concretização de tais direitos, mediante implementação de políticas públicas capazes de promover a proteçáo, 
o atendimento e o desenvolvimento das crianças e adolescentes (CUSTÓDIO; MOREIRA, 2015).

Desse modo, a teoria da proteçâo integral foi adotada como princípio fundamental que por meio de instrumentos normativos e políticos promove estratégias de aplicação e concretização dos direitos às crianças e adolescentes que merecem proteção especial frente a condição de vulnerabilidade que os atinge em razão de estarem em processo de desenvolvimento (CUSTÓDIO; MOREIRA, 2015).

Uma vez consolidada a teoria da proteção integral à criança no ordenamento jurídico pátrio, a proteção à infância é uma das formas de garantir a proteção social. Para tanto, Veronese (2013) destaca que muito mais do que a determinação de direitos na legislação pátria, é imperioso a promoção de políticas públicas capazes de efetivá-los. Como mecanismo de efetivação, a mesma autora cita a importância da descentralizaçáo que representa a responsabilidade entre todos os entes da federação; e na participação da sociedade, estimulando movimentos sociais por meio das associaçóes e ONGs, por exemplo.

A criança é, pois, um ser e, ainda que em desenvolvimento, é detentora da proteção dos direitos humanos que, conforme o próprio nome já diz, são direitos "humanos", bastando possuir a condição de humano para ser titular destes direitos ditos universais, uma vez que não se faz distinção de nacionalidade, gênero, etnia ou religiáo, embora a sua efetiva aplicação prática enfrenta dificuldade em razão do relativismo cultural (COSTA; MARTÍN, 2008).

Conforme destaca Reis (2015), a interpretação que cerca o direito da criança deve ser resultado da aplicação da norma positivada em análise conjunta com os princípios informadores e orientadores. A importância principiológica vai de encontro com a fundamentação da teoria da proteção integral na análise do caso em concreto, não sendo possível, nestes casos, a aplicação literal da norma (REIS, 2015).

Essa tutela integral vai de encontro com o papel fundamental que as crianças desempenham no desenvolvimento da sociedade que indubitavelmente carecem de amparo especial em razão da sua condição de vulnerabilidade enquanto sujeito de direito e ser humano em desenvolvimento. A tríplice responsabilidade compartilhada representa que todos encontram-se responsáveis pela formação digna e saudável da criança de forma conjunta e solidária. É possível afirmar, portanto que, em caso de situação que haja constatação de qualquer tipo de prejuízo à criança, esta deve ser amparada de imediato, consoante determina a legislaçáo internacional, constitucional e infraconstitucional, com fundamento da teoria da proteção integral e nos princípios que a norteiam. Diante da vulnerabilidade que atinge às crianças em razão do seu desenvolvimento, demonstra-se a seguir a proteção relacionada à vulnerabilidade dos idosos em razão do processo de envelhecimento. 


\section{Direito à velhice bem-sucedida}

Assim como as crianças e adolescentes, os idosos também possuem tratamento especial dada a sua condição de vulnerabilidade diretamente ligada a idade. Há alguns anos é possível observar o crescimento da população idosa e a modificação que acontece na pirâmide demográfica.

Segundo dados do IBGE, a população idosa é a que mais cresce no Brasil, influenciada, também, pela diminuição das taxas de fecundidade e mortalidade. Estima-se o aumento de $4 \%$ ao ano no período de 2012 a 2022. Traduzindo esta situação em números, tem-se que em 2010 o registro feito é de 19,6 milhôes, devendo atingir 41,5 milhôes, em 2030, e 73,5 milhôes, em 2060 (IBGE, 2015, https://biblioteca.ibge.gov.br).

Diante deste contexto, urge a necessidade de capacitação da sociedade para fomentar a promoção de uma velhice bem-sucedida, mediante a garantia de políticas públicas que assegurem a dignidade e o bem-estar no momento que a idade madura é atingida e na velhice, embora esta não tenha sido a realidade passada.

$\mathrm{O}$ desenvolvimento da sociedade afetou diretamente o tratamento às pessoas idosas. Enquanto antigamente a comunicação com uma pessoa distante demorava dias com o envio de cartas, atualmente, em consequência ao processo de globalização, é questão de segundos. Da mesma forma, os papeis determinados nas famílias já não existem mais, assim como as mulheres, que antes eram destinadas aos cuidados domésticos e maternos, hoje encontram-se inseridas no mercado de trabalho, com independência. Para a população idosa que antigamente era tratada apenas como pessoas velhas e improdutivas, sendo abandonados à solidão, hoje há maior preocupação com o seu cuidado e bem-estar. (REGERT; ROCHA, 2014).

O cuidado com os idosos é reflexo desse processo. Hoje preza-se de forma mais consciente pelo seu bem-estar. É muito comum ver os próprios idosos preocupados com o envelhecimento saudável, adaptando-se a atividades físicas e intelectuais, afim de vivenciar esta fase da vida com maior dignidade e bem-estar. Da mesma forma, atingida certas limitaçóes físicas e psíquicas, é comum observar o cuidado das famílias ao contratar cuidadores particulares ou clínicas especializadas em cuidados com a população idosa.

Diante desse processo, a Constituição Federal de 1988 representa um importante marco na tutela dos direitos da pessoa idosa. Como objetivo fundamental do país, determina a promoçáo do bem de todos sem discriminaçáo pela idade, consoante texto do artigo $3^{\circ}$, inciso IV "promover o bem de todos, sem preconceitos de origem, raça, sexo, cor, idade e quaisquer outras formas de discriminação”. (BRASIL, 1988, www.planalto.gov.br).

De forma mais específica, o texto constitucional foi além e determinou a tríplice responsabilidade no cuidado da população idosa em seu artigo 230, caput, ao definir que "A família, a sociedade e o Estado têm o dever de amparar as pessoas idosas, assegurando sua participação na comunidade, defendendo sua dignidade e bem-estar e garantindo-lhes o direito à vida" (BRASIL, 1988, www.planalto.gov.br). 
Ainda como forma de assegurar a proteção necessária aos idosos, o constituinte originário dispôs como objetivo do sistema de Seguridade Social a proteção à velhice, consoante artigo 203, inciso I, "a proteção à família, à maternidade, à infância, à adolescência e à velhice". E, como benefício assistencial da seguridade, determinou "a garantia de um salário mínimo de benefício mensal à pessoa portadora de deficiência e ao idoso que comprovem não possuir meios de prover a própria manutençâo ou de tê-la provida por sua família [...]”, conforme o texto do inciso V do mesmo artigo (BRASIL, 1988, www.planalto.gov.br).

Em 1996 foi regulamentada a Lei n ${ }^{\circ} .8 .842$ de 04 de janeiro de 1994, que dispóe acerca Política Nacional do Idoso, importante marco infraconstitucional ao definir como objetivo "assegurar os direitos sociais do idoso, criando condiçôes para promover sua autonomia, integração e participação efetiva na sociedade" (BRASIL, 1994, www.planalto.gov.br). Após, em 2001, houve importante alteração na legislação, ao determinar a prioridade de tramitação nos processos judiciais em que figurem as pessoas idosas, conforme texto Lei ${ }^{\circ}$. 10.173/2001 (ANTONELO, 2010).

Logo após, em 2003 foi editada a Lei no. 10.741/2003 dispondo acerca do Estatuto do Idoso, que enfatizou, novamente, a responsabilidade da família, da comunidade, da sociedade e do Poder Público em assegurar ao idoso a tutela integral e necessária. Ainda, trouxe em seu texto a garantia da prioridade absoluta na efetivação do direito à vida, à saúde, à alimentação, à educaçáo, à cultura, ao esporte, ao lazer, ao trabalho, à cidadania, à liberdade, à dignidade, ao respeito e à convivência familiar e comunitária ${ }^{5}$.

Dentre as prioridades absolutas, o estatuto indica em seu artigo $3^{\circ}$, parágrafo $1 \S^{\circ}$ inciso I e III, o atendimento preferencial e a "destinação privilegiada de recursos públicos nas áreas relacionadas com a proteção ao idoso". Ainda no mesmo artigo, o texto legal indica, consoante inciso V, "a priorização do atendimento do idoso por sua própria família, em detrimento do atendimento asilar, exceto dos que não a possuam ou careçam de condiçóes de manutenção da própria sobrevivência" (BRASIL, 2003, www.planalto.gov.br).

É inegável a tutela especial ao idoso dada a sua condição de vulnerabilidade. A constituição federal e a legislação infraconstitucional dão conta de assegurar o direito a velhice de forma digna. $\mathrm{O}$ artigo $2^{\circ}$ do Estatuto do Idoso traduz esta ideia quando determina a "preservação

$5 \$ 1^{\circ} \mathrm{A}$ garantia de prioridade compreende: I - atendimento preferencial imediato e individualizado junto aos órgãos públicos e privados prestadores de serviços à população; II - preferência na formulaçấo e na execuçâo de políticas sociais públicas específicas; III - destinação privilegiada de recursos públicos nas áreas relacionadas com a proteção ao idoso; IV - viabilização de formas alternativas de participaçáo, ocupação e convívio do idoso com as demais geraçôes; $\mathrm{V}$ - priorização do atendimento do idoso por sua própria família, em detrimento do atendimento asilar, exceto dos que não a possuam ou careçam de condiçôes de manutenção da própria sobrevivência; VI - capacitaçáo e reciclagem dos recursos humanos nas áreas de geriatria e gerontologia e na prestação de serviços aos idosos; VII - estabelecimento de mecanismos que favoreçam a divulgação de informações de caráter educativo sobre os aspectos biopsicossociais de envelhecimento; VIII - garantia de acesso à rede de serviços de saúde e de assistência social locais. IX - prioridade no recebimento da restituiçáo do Imposto de Renda (BRASIL, 2003, www.planalto.gov.br). 
de sua saúde física e mental e seu aperfeiçoamento moral, intelectual, espiritual e social, em condiçôes de liberdade e dignidade".

Deste modo, em caso de doença da pessoa idosa, esta tem o direito a família como responsável pelo seu cuidado em conjunto com a tutela do Estado e da comunidade, razão pela qual fundamenta-se a importância da ampliação da proteção social de forma que assegure às famílias, em reflexo aos cuidados das crianças e idosos, a tutela necessária em situaçóes de infortúnios e riscos sociais existentes.

\section{Auxílio-doença parental: política pública previdenciária na proteçáo das populaçóes vulneráveis}

O estudo em contento objetiva a análise da necessidade de criação de políticas públicas de Seguridade Social para efetivação dos direitos humanos, a partir de uma análise teórico metodológica da proteção integral à família e à criança. Para tanto, neste contexto de necessidade de ampliação da proteção social que se defende a criação deste benefício aos segurados do Regime Geral da Previdência Social.

A Previdência Social é um dos pilares que compóe o atual sistema de Seguridade Social, conforme determina o texto constitucional em seu art. 194. Esta é organizada sob a forma de RGPS, de caráter contributivo e compulsório, na medida em que o artigo 201 da Constituição Federal (BRASIL, 1988, www.planalto.gov.br) prevê a filiação obrigatória ao regime daqueles que auferem renda. Os benefícios a quem dela é segurado darão cobertura a eventos de invalidez, morte e idade avançada, da mesma forma que protege a gestante, o desempregado e o preso (VIANNA, 2012).

Muito embora o RGPS seja utilizado como sinônimo de Previdência Social - em razão de abranger a maioria dos trabalhadores - existe dois regimes básicos previdenciários brasileiros: o já mencionado Regime Geral, e o Regime Próprio da Previdência Social - RPPS, ambos com a característica da filiação compulsória (IBRAHIM, 2012).

A razão de ser do nome "Auxílio-Doença Parental" é em função de se tratar de um auxílio para o familiar e não ao doente propriamente dito, ou seja, decorre das situaçôes em que o segurado ou a segurada torna-se, temporariamente, incapaz para realizar as atividades laborativas em razão da enfermidade de um membro familiar, seja este, mãe, pai, cônjuge, filho ou afins que a lei determinar.

Atualmente, os benefícios garantidos aos segurados da Previdência Social, ainda que consideráveis, carecem de ampliação da proteção frente a certas necessidades urgentes e recorrentes que a população enfrenta, razão pela qual se propóe a ampliação do rol dos benefícios no RGPS.

Dentre os benefícios assegurados pelo RGPS, na sua essência, o Auxílio-Doença é o que mais se assemelha ao benefício abordado pelo presente trabalho, conforme o próprio nome já 
demonstra, tendo em vista que aquele é o benefício que atualmente ampara os segurados com incapacidade temporária para o trabalho, nos moldes previstos pelo art. 59 da Lei 8.213/916.

Contudo, o artigo acima mencionado não faz qualquer menção à incapacidade do segurado ou a possibilidade do segurado de afastar-se do trabalho para cuidados de familiar enfermo. Nesse sentido, embora a Previdência Social tenha expressiva cobertura aos infortúnios que atingem a população brasileira, ainda é escassa no que diz respeito aos encargos familiares, motivo pelo qual há segurados desamparados pelo sistema, eis que a falta de regulamentação legal do benefício do Auxílio-Doença Parental limita a proteção concedida pelo RGPS.

Ademais, a ampliação da proteção à família, que desde os primórdios representa a base da sociedade, o início da convivência com outros indivíduos (onde se aprende os primeiros valores e regras sociais), seja esta sanguínea ou afetiva, é expressamente amparada pela Constituição Federal que determina, em seu artigo 226 (BRASIL, 1988, www.planalto.gov.br), proteção especial do Estado para com ela. Da mesma forma, o artigo $1^{\circ}$ da Lei no 8.213/91 ao dispor dos Planos e Benefícios da Previdência Social, prevê a proteção previdenciária aos encargos familiares?

A viabilidade jurídica para a criação do benefício encontra respaldo nos preceitos básicos assegurados constitucionalmente aos cidadáos, dentre eles, a dignidade da pessoa humana, a proteção à família e a promoção da justiça social, além da proteção especial às crianças e idosos. Imagina-se uma mãe que precisa deixar o emprego para cuidar de um filho com câncer. Ou uma filha, que precisa deixar suas atividades laborativas para cuidar da sua mãe em estado grave de saúde. Ambas estarão vivenciando o estado crítico da saúde de um ente querido, além da redução drástica do capital financeiro essencial nesses casos.

Ademais, estudos revelam que a presença de um familiar, principalmente nos casos de doentes mais vulneráveis, como crianças e idosos, muitas vezes atinge positivamente a recuperaçáo que se torna mais ágil e menos dolorida ao paciente enfermo, consoante pesquisa realizada nas Unidades de Terapia Intensiva (UTI) pediátrica e neonatal no Hospital do Paraná ${ }^{\circ}$.

6 Art. 59. O auxílio-doença será devido ao segurado que, havendo cumprido, quando for o caso, o período de carência exigido nesta Lei, ficar incapacitado para o seu trabalho ou para a sua atividade habitual por mais de 15 (quinze) dias consecutivos.

Parágrafo único. Não será devido auxílio-doença ao segurado que se filiar ao Regime Geral de Previdência Social já portador da doença ou da lesão invocada como causa para o benefício, salvo quando a incapacidade sobrevier por motivo de progressão ou agravamento dessa doença ou lesão (BRASIL, 1991, www.planalto.gov.br).

7 Art. $1^{\circ}$ A Previdência Social, mediante contribuiçâo, tem por fim assegurar aos seus beneficiários meios indispensáveis de manutenção, por motivo de incapacidade, desemprego involuntário, idade avançada, tempo de serviço, encargos familiares e prisão ou morte daqueles de quem dependiam economicamente (BRASIL, 1991, www.planalto.gov.br).

8 Sobre o assunto, segue trecho da pesquisa realizada nas Unidades de Terapia Intensiva (UTI) pediátrica e neonatal no Hospital do Paraná O estresse da criança é inevitável durante o período de internação na UTI, visto que vários sấo os fatores causadores deste distúrbio, entre os quais o medo, a dor, os longos períodos de vigília, a mudança do ambiente e a ausência da família. Os resultados encontrados mostram que os profissionais têm conhecimento do estresse e do sofrimento que a criança vivencia diante da à (sic) internaçáo, pois a mudança de ambiente lhe causa desequilíbrio emocional, principalmente quando não pode compartilhar com a família esta nova situaçáo vivencial. A retirada da criança do ambiente em que ela vive gera angústia e dor, que a criança tem dificuldade em trabalhar. (M 6) Em contrapartida, a presença da família, em especial a da mãe, geralmente promove e mantém a inter-relação criança/ família/equipe, neutraliza os efeitos negativos 
Desta forma, pessoas acometidas de doenças graves estáo expostas a inúmeras situações desagradáveis e procedimentos dolorosos, que os tornam inseguros e angustiados, especialmente às crianças e aos idosos. $\mathrm{Na}$ medida em que a enfermidade de algum destes, por exemplo, se torna mais eficaz na presença e com os cuidados de um familiar, a viabilidade jurídica na criação do benefício encontra respaldo no Estatuto da Criança e do Adolescente em seu art. $4^{\circ}$ e no Estatuto do Idoso em seu art. $3^{\circ}$, que preveem a absoluta prioridade na efetivação dos direitos destes, considerados vulneráveis, sendo dever da família, da comunidade, da sociedade em geral e do poder público, assegurar, dentre eles, o direito à vida e à saúde (COSTA; NUNES, 2016).

A própria Lei no 8.069/90 que dispóe sobre o Estatuto da Criança e do Adolescente, em seu art. 12, determina que os estabelecimentos de atendimento à saúde proporcionem a um dos pais ou responsável condiçôes para permanência em tempo integral no estabelecimento nos casos de internação de criança ou adolescente (BRASIL, 1990, www.planalto.gov.br).

Da mesma forma, o Decreto no 99.710/1990, que dispôe sobre a Convenção sobre os Direitos da Criança, em seu art. 26 corrobora a tutela integral às crianças quando determina a assistência da criança, via Previdência Social?.

Ademais, com a adoção da Doutrina da Proteção Integral, toda criança é merecedora de direitos próprios e especiais que, necessitam de proteção especializada, diferenciada e integral (VERONESE, 2013).

Nesse sentido, a ampliação da proteção social, via políticas públicas de Seguridade Social representa uma forma de concretização desta proteção especial às crianças e aos idosos, em situaçóes que estes encontram-se acometidos de enfermidades que os tiram, ainda que temporariamente, do seio da sociedade, em uma internaçáo hospitalar, por exemplo. Em situaçóes como esta, mais do que direito ao familiar, é direito absoluto da criança o acompanhamento de um ente familiar ${ }^{10}$.

Da mesma forma é a proteção especial destinada a população idosa, consoante legislação específica e adoção da proteção integral também a estes, que em razão da sua condição de envelhecimento, carece de tutela integral e diferenciada.

decorrentes da separação, melhora sua adaptação ao hospital, facilita a aceitaçáo do tratamento e ameniza os fatores estressantes da doença, dos procedimentos e da hospitalizaçáo (MOLINA et al, 2006, p. 440, grifo próprio).

9 1. Os Estados Partes reconhecerão a todas as crianças o direito de usufruir da previdência social, inclusive do seguro social, e adotaráo as medidas necessárias para lograr a plena consecução desse direito, em conformidade com sua legislação nacional. 2. Os benefícios deverão ser concedidos, quando pertinentes, levando-se em consideração os recursos e a situação da criança e das pessoas responsáveis pelo seu sustento, bem como qualquer outra consideração cabível no caso de uma solicitação de benefícios feita pela criança ou em seu nome (BRASIL, 1990, www.planalto.gov.br).

10 Nesse sentido, Custódio (2006, p. 32-33). Indica que "[...] todos os atos relacionados ao atendimento das necessidades da criança e do adolescente devem ter como critério a perspectiva dos seus melhores interesses. Essa perspectiva é orientadora das açóes da família, da sociedade e do Estado, que nos processos de tomada de decisão, sempre, devem considerar quais as oportunidades e facilidades que melhor alcançam os interesses da infância”. 


\section{Consideraçóes finais}

A existência de riscos sociais torna inquestionável a necessidade da criação do Auxíliodoença Parental que por sua vez representa uma forma de garantir a proteção especial à família, em especial às crianças e idosos, diante dos benefícios aos segurados do Regime Geral da Previdência Social.

Dentre as consequências positivas da ampliação da proteção social, está o direito ao desenvolvimento de uma vida digna no desenvolvimento das crianças e no envelhecimento dos idosos. Isto porque, as pesquisas confirmam que a presença de um ente próximo da família, além de atenuar a dor do paciente, contribui no tratamento, facilitando, em alguns casos, à cura ou melhora do quadro.

É inequívoco a determinação expressa da Constituição Federal de 1988 acerca dos direitos sociais. Para tanto, a forma de concretizar a proteção social é via construção de políticas públicas capazes de garantir a tutela especial garantida às crianças e idosos, além de garantir o bem-estar social idealizado pelo constituinte.

Assim, considerando a instituição constitucional da previdência social como um dos instrumentos capazes de garantir o bem-estar social, a criação do benefício previdenciário do Auxílio-Doença Parental representa uma política pública capaz de concretizar os direitos humanos, bem como assegurar a proteçáo integral às familias, assegurando a garantia ao desenvolvimento de uma vida digna.

\section{Referências}

ANTONELO, Josiane Borghetti. Politicas Públicas de (im)previdência social: uma análise da efetivação da cidadania dos idosos no brasil frente aos benefícios previdenciários auferidos. 160 f. Dissertação (Programa de Pós-Graduação em Direitos Sociais e Políticas Públicas - Mestrado). Universidade de Santa Cruz do Sul, Santa Cruz do Sul, 2010.

BRASIL. Constituição (1988). Constituição da República Federativa do Brasil. Brasília, DF: Senado Federal, 1988. Disponível em: <http://www.planalto.gov.br/ccivil_03/ constituicao/constituicaocompilado.htm>. Acesso em: 31 mai. 2019.

BRASIL. Decreto n. 99.710, de 21 de novembro 1990. Promulga a Convenção sobre os Direitos da Criança. Diário Oficial [da] República Federativa do Brasil, Brasília, DF, 22 nov. 1990. Disponível em: <http://www.planalto.gov.br/ccivil_03/ decreto/1990-994/d99710.htm>. Acesso em: 04 jun. 2019.

BRASIL. Lei n. 8.069, de 13 de julho 1990. Dispóe sobre o Estatuto da Criança e do Adolescente e dá outras providências. Diário Oficial [da] República Federativa do Brasil, 
Brasília, DF, 16 jul. 1990. Disponível em: <http://www.planalto.gov.br/ccivil_03/leis/ L8069.htm>. Acesso em: 02 jun. 2019.

BRASIL. Lei n. 8.213, de 24 de julho 1991. Dispóe sobre os Planos de Benefícios da Previdência Social e dá outras providências. Diário Oficial [da] República Federativa do Brasil, Brasília, DF, 25 jul. 1991. Disponível em: <http://www.planalto.gov.br/ ccivil_03/leis/L8213cons.htm>. Acesso em: 12 mar. 2019.

BRASIL. Lei 8.842, de 4 de janeiro de 1994. Dispóe sobre a política nacional do idoso, cria o Conselho Nacional do Idoso e dá outras providências. Diário Oficial [da] República Federativa do Brasil, Brasília, DF, 5 jan. 1994. Disponível em <http://www. planalto.gov.br/ccivil_03/leis/18842.htm>. Acesso em: 25 jun. 2019.

BRASIL. Lei n. 10.741, de 1 de outubro de 2003. Dispóe sobre o Estatuto do Idoso e dá outras providências. Diário Oficial [da] República Federativa do Brasil, Brasília, DF, 3 dez. 2003. Disponível em: <http://www.planalto.gov.br/ccivil_03/leis/2003/110.741. htm>. Acesso em: 25 jun. 2019.

COSTA, M. M. M. da; MARTÍN, Belloso Núria. Diálogos Jurídicos entre o Brasil e Espanha: da exclusão social aos direitos sociais. 1. ed. Porto Alegre: Imprensa Livre, 2008.

COSTA, M.M.M. da; NUNES, J.B.A. Auxílio doença parental: Viabilidade e necessidade de sua criação com o fito de garantir a dignidade da pessoa humana, o bem estar e justiça social. In: XIII SEMINÁRIO INTERNACIONAL DE DEMAN DAS SOCIAIS E POLÍTICAS PÚBLICAS NA SOCIEDADE CONTEMPORÂNEA, 2016, Santa Cruz do Sul. Anais... Santa Cruz do Sul. Disponível em: <http://online. unisc.br/acadnet/anais/index.php/sidspp/article/view/15852/3749>. Acesso em: 25 jun. 2019.

CUSTÓDIO, André Viana. A exploração do trabalho infantil doméstico no Brasil contemporâneo: limites e perspectivas para sua erradicação. Tese. $282 \mathrm{f}$. (Doutorado em Direito). Curso de Pós-Graduação em Direito, Universidade Federal de Santa Catarina, Florianópolis, 2006

CUSTÓDIO, André Viana. Teoria da proteção integral: pressuposto para compreensão do direito da criança e do adolescente. Revista do Direito, Santa Cruz do Sul, p. 22-43, jan. 2008. ISSN 1982-9957. Disponível em: <https://online.unisc.br/seer/index.php/ direito/article/view/657/454>. Acesso em: 25 jun. 2019. doi:https://doi.org/10.17058/ rdunisc.v0i29.657.

CUSTÓDIO, André Viana; MOREIRA, Rafael Bueno da Rosa. A garantia do direito à educação de crianças e adolescentes no contexto das políticas públicas brasileiras.

Revista Brasileira de Políticas Públicas, Brasília, v. 5, no 1, 2015 p. 223-245. 
GORCZEVSKI, Clovis. A necessária revisão do conceito de cidadania: movimentos sociais e novos protagonistas na esfera pública democrática / Clovis Gorczevski e Nuria Belloso Martin. - Santa Cruz do Sul: EDUNISC, 2011.

IBRAHIM, Fábio Zambitte. Curso de direito previdenciário. 17. ed. Niteroi: Impetus, 2012.

INSTITUTO BRASILEIRO DE GEOGRAFIA E ESTATÍSTICA. Mudança demográfica no Brasil no início do século XXI: subsídios para as projeções da população. Disponível em: <https://biblioteca.ibge.gov.br/index.php/biblioteca-catalog o?view=detalhes\&id=293322>. Acesso em 25 jun. 2019.

MARCONDES, Danilo. Textos básicos de ética: de Platão à Foucault. 4. ed. Rio de Janeiro: Zahar, 2009.

MOLINA, R. C. M. et al. Presença da Família nas Unidades de Terapia Intensiva Pediátrica e Neonatal: Visão da Equipe Multidisciplinar. Disponível em: <http://www. scielo.br/pdf/ean/v11n3/v11n3a07>. Acesso em: 23 jul. 2017.

REGERT, Romi Margô; ROCHA, Claudine Rodembusch. Direito, cidadania e políticas públicas: velhice bem sucedida. In: XV Seminário Internacional Demandas Sociais e Políticas Públicas na Sociedade Contemporânea, 2018, Santa Cruz do Sul. Anais... Santa Cruz do Sul. Disponível em: <https://online.unisc.br/acadnet/anais/ index.php/sidspp/article/view/11841>. Acesso em: 25 jun. 2019.

REIS, Suzéte da Silva. Açóes e estratégias de politicas públicas para o enfrentamento da exploração do trabalho infantil nos meios de comunicação no marco da teoria da proteçâo integral aos direitos da criança e do adolescente. 2015. 264 f. Tese (Doutorado). Universidade de Santa Cruz do Sul, 2015

VERONESE, Josiane Rose Petry. A proteção integral da criança e do adolescente no direito brasileiro. Brasília: Rev. TST, vol. 79. Disponível em: <https://juslaboris.tst. jus.br/bitstream/handle/20.500.12178/38644/003_veronese.pdf>. Acesso em 03 jun. 2019.

VIANNA, João Ernesto Aragonés. Curso de direito previdenciário. 5. ed. São Paulo: Atlas, 2012. 